\title{
Inflammatory responses after vitrectomy with vitreous substitutes in a rabbit model
}

\author{
Henrik Barth ${ }^{1}$ (D) Sven Crafoord ${ }^{2} \cdot$ Karin Arnér $^{1} \cdot$ Fredrik Ghosh $^{1}$
}

Received: 13 September 2018 / Revised: 27 November 2018 / Accepted: 7 January 2019 / Published online: 17 January 2019

(C) The Author(s) 2019

\begin{abstract}
Purpose To investigate the inflammatory response of current and future potential vitreous substitutes in an experimental in vivo vitrectomy model.

Methods Twenty-five gauge pars plana vitrectomy was performed in the right eye of 60 pigmented rabbits, with subsequent injection of $0.5-1.0 \mathrm{ml}$ of Healaflow ${ }^{\circledR}$ (cross-linked hyaluronic acid, $n=12$ ), Bio-Alcamid ${ }^{\circledR}$ (polyalkylimide, $n=8$ ), silicone oil $(n=12)$, or balanced saline solution (BSS, $n=28$ ). Postoperative clinical evaluation was performed; and the rabbits were sacrificed at 1 day, 1 week, or 1 month. The eyecups were then examined macroscopically; the retinas sectioned and stained with hematoxylin and eosin (Htx), and immunohistochemically labeled for glial fibrillary acidic protein (GFAP), CD45, galectin3, CD68, and CD20. Unoperated left eyes from treated animals as well as eyes from untreated animals were used as controls. Results Vitrectomy without major complications was achieved in 46/60 eyes. The remaining 14 eyes were analyzed separately. One eye developed endophthalmitis after 1 week and was excluded. Eyes treated with Healaflow ${ }^{\circledR}$, silicone oil, and BSS had a comparable appearance macroscopically and in Htx-stained sections, whereas Bio-Alcamid®-injected eyes exhibited increased macroscopic inflammation and severely affected retinas. GFAP upregulation was present in all treatment groups, most prominent in eyes treated with Bio-Alcamid® and silicone oil. Upregulation of CD45 and CD68 in the inner retina and vitreous space was most prominent with Bio-Alcamid® treatment, and these eyes together with their silicone oil-treated counterparts also displayed a stronger upregulation of CD20-labeled cells compared with remaining groups. General upregulation of galectin-3, mainly in the inner retina, was found in all groups. In eyes with perioperative complications, labeling of CD45, CD68, and especially GFAP was comparably high.

Conclusions We here describe differences in the postsurgery inflammatory profiles of existing and potential vitreous substitutes. Bio-Alcamid ${ }^{\circledR}$ and silicone oil display severe signs of gliosis and inflammation, whereas Healaflow ${ }^{\circledR}$ elicits minimal reactions comparable with BSS, highlighting its potential application as a vitreous substitute in a future clinical setting.
\end{abstract}

Keywords Vitreous substitute $\cdot$ Vitreous $\cdot$ Vitreoretinal surgery $\cdot$ Methods $\cdot$ Hyaluronic acid $\cdot$ Hydrogel

\section{Introduction}

The vitreous fills essential physiological functions in the healthy eye, including mechanical and metabolic support, but

For: Graefe's Archive for Clinical and Experimental Ophthalmology

Henrik Barth

henrik.barth@med.lu.se

1 Department of Ophthalmology, Lund University, BMC D10, 22184 Lund, Sweden

2 Department of Ophthalmology, Faculty of Medicine and Health, Örebro University, Örebro University Hospital, Orebro, Sweden also plays a key role in the pathogenesis of vitreoretinal disease. A range of conditions including retinal detachment, severe diabetic complications, penetrating trauma, and macular hole all require surgical intervention using vitrectomy. As the vitreous is removed during the vitrectomy, there is a need for its replacement — either by balanced saline solution (BSS), or a tamponading agent such as gas or silicone oil facilitating the healing after surgery [1].

Prolonged inflammatory reactions have been described after cataract surgery [2], and it is a well-known clinical fact that the vitrectomy procedure likewise elicits inflammation as part of the healing process. Topical steroids are therefore routinely prescribed postoperatively to prevent symptoms of uveitis, and to limit other detrimental effects 
$[3,4]$. The specific mechanisms of the postsurgical immune response include elevated levels of cytokines such as IL-6, IL-8, MCP-1, and TGF- $\beta 1$ in the aqueous humor [5]. The retinal response to the vitrectomy procedure is, however, incompletely known.

Existing tamponading agents are prone to side effects and drawbacks such as secondary glaucoma, uveitic reactions, impaired vision, and the need for a prolonged period of prone positioning [6-8]. For more complex cases, where a tamponade is needed for an extended period of time, the only current option is silicone oil. Long-term treatment with silicone oil is associated with complications such as inflammation, proliferation of epiretinal and subretinal membranes, optic nerve atrophy, and retinal toxicity [9-13].

To improve biocompatibility and overcome the complications associated with current tamponading compounds, research into novel vitreous substitutes has been ongoing for several decades. One of the most important side effects limiting the practical use of many potential vitreous substitutes is inflammatory reactions [14-16]. An example of these is the foreign body reaction - a type of cellular inflammation characterized by macrophages, giant cell formation, and fibrosis [17]. Exposure to experimental biomaterials, such as intravitreally injected poly lactic-co-glycolic acid (PLGA) polymer microspheres and rods, has reportedly elicited this kind of reaction [18]. Furthermore, similar inflammatory responses have been reported following the injection of vitreous substitutes such as perfluoro-n-octane (PFO) [19, 20], perfluorohexyloctane [21], and silicone oil $[22,23]$.

In earlier experiments by our group, treatment of rabbit eyes with Bio-Alcamid ${ }^{\circledR}$ (polyalkylimide), a hydrogel previously used as subcutaneous filler in reconstructive plastic surgery, caused macro- and microscopical edema, neuronal degeneration, as well as loss of function [24]. We have additionally reported retinal degeneration using this compound in a novel in vitro setup [25]. In contrast, further experiments with another potential vitreous substitute, Healaflow ${ }^{\circledR}$ (crosslinked hyaluronic acid) in an in vivo rabbit model, revealed excellent biocompatibility [26].

Table 1 Summary of peri- and postoperative data. The status shown is at the end of follow-up. Abbreviations: Routine vitrectomy with BSS (BSS), treatment with Healaflow ${ }^{\circledR}(\mathrm{HF})$, treatment with Silicone oil (SiO), treatment with Bio-Alcamid® (BA), and significant complications (Compl)

\begin{tabular}{|c|c|c|c|c|c|}
\hline Treatment & Follow-up time & Number & Perioperative complications & Cataract present & Postop status (retina and vitreous) \\
\hline BSS & 1 day & 4 & $\begin{array}{l}\text { Limited lens touch in one case. Limited retinal } \\
\text { hemorrhage in one case. Vitreous } \\
\text { hemorrhage in one case }\end{array}$ & $0 / 4$ & $\begin{array}{l}\text { Macroscopic vitreous hemorrhage } \\
\text { in one case }\end{array}$ \\
\hline BSS & 1 week & 6 & $\begin{array}{l}\text { Limited lens touch in two cases. Vitreous } \\
\text { hemorrhage in two cases }\end{array}$ & $2 / 6$ & $\begin{array}{l}\text { Macroscopic vitreous hemorrhage } \\
\text { in two cases }\end{array}$ \\
\hline BSS & 1 month & 4 & $\begin{array}{l}\text { Limited lens touch in one case. Small retinal } \\
\text { hemorrhage in one case. Vitreous } \\
\text { hemorrhage in one case }\end{array}$ & $2 / 4$ & $\mathrm{Ok}$ \\
\hline $\mathrm{HF}$ & 1 day & 4 & Limited lens touch in one case & $0 / 4$ & Ok \\
\hline $\mathrm{HF}$ & 1 week & 4 & $\begin{array}{l}\text { Limited lens touch in one case. Limited retinal } \\
\text { touch in one case }\end{array}$ & $2 / 4$ & One limited retinal break otherwise ok \\
\hline $\mathrm{HF}$ & 1 month & 4 & $\begin{array}{l}\text { Limited lens touch in two cases. Limited retinal } \\
\text { touch in two cases }\end{array}$ & $2 / 4$ & Ok \\
\hline $\mathrm{SiO}$ & 1 day & 7 & $\begin{array}{l}\text { Limited lens touch in one case. Limited retinal } \\
\text { touch in one case }\end{array}$ & $0 / 4$ & One limited retinal break, otherwise ok \\
\hline $\mathrm{SiO}$ & 1 week & 4 & No complications & $1 / 4$ & Ok \\
\hline $\mathrm{SiO}$ & 1 month & 4 & Limited lens touch in one case & $0 / 4$ & Ok \\
\hline BA & 1 week & 4 & $\begin{array}{l}19 \text { G sclerotomy sutured. Lens touch in one } \\
\text { case. Retinal touch in one case }\end{array}$ & $4 / 4$ & $\begin{array}{l}\text { Injection and conjunctival edema. } \\
\text { Vitreous cloudiness infiltrates in } \\
\text { all four cases. RD in one case }\end{array}$ \\
\hline $\mathrm{BA}$ & 1 month & 4 & $\begin{array}{l}19 \mathrm{G} \text { sclerotomy sutured. Lens touch in one } \\
\text { case. Vitreous hemorrhage in one case }\end{array}$ & $4 / 4$ & $\begin{array}{l}\text { Injection and conjunctival edema. } \\
\text { Vitreous cloudiness in all four cases. }\end{array}$ \\
\hline Compl & 1 day & 4 & $\begin{array}{l}\mathrm{RD} \text { from the infusion in and retinal touch in } \\
\text { one case. Retinal touch in three cases. } \\
\text { Lens touch in four cases }\end{array}$ & $3 / 4$ & $\begin{array}{l}\text { Almost complete RD in one case. } \\
\text { Retinal breaks in three cases. } \\
\text { Vitreous hemorrhage in one case }\end{array}$ \\
\hline Compl & 1 week & 5 & $\begin{array}{l}\text { Lens touch in three cases. Retinal touch in } \\
\text { three cases. Limited RD from the infusion } \\
\text { in one case }\end{array}$ & $4 / 4$ & $\begin{array}{l}\text { Peripheral RD in one case } \\
\text { Retinal break in three cases }\end{array}$ \\
\hline Compl & 1 month & 4 & $\begin{array}{l}\text { Fluctuating IOP, retinal touch, and vitreous } \\
\text { hemorrhage in one case. Retinal touch } \\
\text { in three cases }\end{array}$ & $3 / 4$ & $\begin{array}{l}\text { Subtotal RD in one case. Retinal breaks } \\
\text { in three cases }\end{array}$ \\
\hline
\end{tabular}


Table 2 Specification of immunohistochemical markers

\begin{tabular}{|c|c|c|c|c|c|}
\hline & Antibody name & Target structure & Species & Dilution & Source \\
\hline \multicolumn{6}{|l|}{ Antigen } \\
\hline CD45 & $\mathrm{L} 12 / 201$ & Pan-leukocyte & Mouse monoclonal & $1: 100$ & Bio-Rad, Oxford, UK \\
\hline Galactein-3 & Galactein-3 antibody & Mainly microglia & Chicken & $1: 100$ & $\begin{array}{l}\text { A kind gift from Prof. H Leffler, } \\
\text { Lund, Sweden }\end{array}$ \\
\hline CD68 & EBM11 & Macrophages & Mouse monoclonal & $1: 200$ & Agilent DAKO, Santa Clara, USA \\
\hline CD20cy & L26 & B lymphocytes & Mouse monoclonal & $1: 200$ & Agilent DAKO, Santa Clara \\
\hline $\begin{array}{l}\text { GFAP, glial fibrillary } \\
\text { acidic protein }\end{array}$ & G-A-5 & $\begin{array}{l}\text { Astrocytes, activated } \\
\text { Müller cells }\end{array}$ & Mouse monoclonal & $1: 200$ & Chemicon International, CA, USA \\
\hline \multicolumn{6}{|l|}{ Secondary antibody } \\
\hline FITC & Anti-mouse IgG FITC conjugate & Anti-mouse & Goat & $1: 200$ & Sigma, St Louis, MO, USA \\
\hline Texas Red & Anti-IgY Texas Red conjugate & Anti-chicken & Rabbit & $1: 200$ & Abcam, Cambridge, UK \\
\hline
\end{tabular}

We here wanted to further elucidate the retinal inflammatory reactions elicited by vitrectomy and treatment with vitreous substitutes. For this purpose, we chose to investigate the two previously described gels with known differences in biocompatibility, and compare them to BSS and silicone oil, the two tamponades currently used clinically. In order to explore both the internal and external immune responses, we investigate markers for gliosis (glial fibrillary acidic protein [GFAP]), neuroinflammation (galectin-3), as well as markers for phagocytic and antigen-presenting cells of the cellular immune response (CD45, CD68, and CD20) [27-31].

\section{Materials and methods}

\section{Animals}

In this study, 60 at least 4-month-old, pigmented rabbits obtained from a local breeder were used. The breeder is continually certified and controlled by the applicable governmental authorities, has many years of experience, and is a longtime supplier to our institution. All proceedings and animal treatment were in accordance with the guidelines and requirements of the government committee on animal experimentation at
Table 3 Summary of histology and immunohistochemistry. Grading: (+) sporadic, + low, ++ moderate, +++ high, ++++ very high. Abbreviations: Routine vitrectomy with BSS (BSS), treatment with
Healaflow ${ }^{\circledR}(\mathrm{HF})$, treatment with Silicone oil $(\mathrm{SiO})$, treatment with Bio-Alcamid® (BA), and significant complications (Compl)

\begin{tabular}{|c|c|c|c|c|c|c|c|c|}
\hline Treatment & Follow-up time & Number & HTX & GFAP & CD45 & Gal-3 & CD68 & CD20 \\
\hline BSS & 1 day & 4 & $\mathrm{Ok}$ & $(+)-+$ & $(+)-+$ & ++ & --+ & $--(+)$ \\
\hline BSS & 1 week & 6 & Erythrocytes on the ILM in one case & ++ & ++ & ++ & $(+)$ & $--(+)$ \\
\hline BSS & 1 month & 4 & Erythrocytes on the ILM in one case & +-++++ & +++ & ++ & --++ & $--(+)$ \\
\hline $\mathrm{HF}$ & 1 day & 4 & $\mathrm{Ok}$ & + & + & ++ & - & $--(+)$ \\
\hline $\mathrm{HF}$ & 1 week & 4 & Retinal ruptures in two cases & ++-+++ & + & ++ & $(+)-+$ & - \\
\hline $\mathrm{HF}$ & 1 month & 4 & Retinal ruptures in two cases & $(+)-+++$ & $(+)-+$ & ++ & $(+)$ & - \\
\hline $\mathrm{SiO}$ & 1 day & 7 & Retinal ruptures in one case & $(+)$ & ++ & ++ & + & $(+)$ \\
\hline $\mathrm{SiO}$ & 1 week & 4 & $\mathrm{Ok}$ & ++-+++ & +++ & ++ & $(+)$ & - \\
\hline $\mathrm{SiO}$ & 1 month & 4 & $\mathrm{Ok}$ & +-++ & ++ & ++ & - & - \\
\hline BA & 1 week & 4 & $\begin{array}{l}\text { Thin to very thin retina with loss of } \\
\text { lamination. Pyknosis. RD in one } \\
\text { case. Cells in vitreous }\end{array}$ & ++++ & +++ & +++ & ++ & ++++ \\
\hline BA & 1 month & 4 & $\begin{array}{l}\text { Extremely thin retina with loss of } \\
\text { lamination. Pyknosis }\end{array}$ & ++++ & +++ & +++ & +++ & $(+)$ \\
\hline Compl & 1 day & 4 & $\begin{array}{l}\text { Almost complete RD in one case. } \\
\text { Retinal ruptures in three cases }\end{array}$ & ++ & +-+++ & ++ & +-+++ & +-++ \\
\hline Compl & 1 week & 5 & $\begin{array}{l}\text { RD in one case. Retinal rupture in } \\
\text { three cases }\end{array}$ & +++ & +-+++ & +++ & +-++ & - \\
\hline Compl & 1 month & 4 & $\begin{array}{l}\text { RD in one case. Retinal rupture in } \\
\text { three cases }\end{array}$ & +++-++++ & ++ & ++ & + & - \\
\hline
\end{tabular}




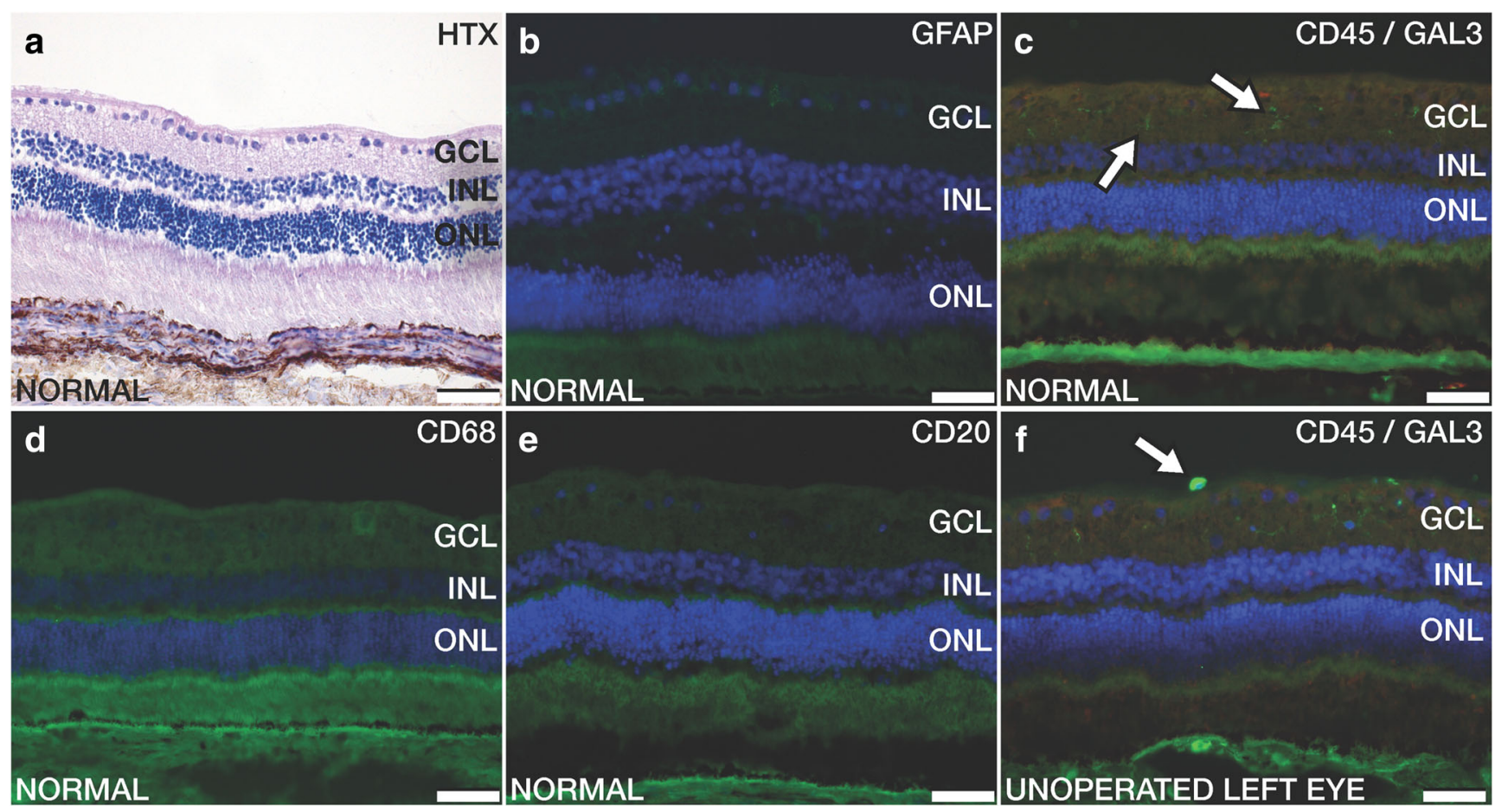

Fig. 1 Cryosections of normal rabbit retina labeled with hematoxylin and eosin (a), glial fibrillary acidic protein (GFAP, activated Müller cells) (b), CD45 (pan-leukocyte, green; examples indicated by arrows) and Galactein-3 (mainly microglia, red) (c), CD68 (macrophage) (d), and CD20 (B-lymphocytes) (e). Also depicted: a cryosection of retina from

Lund University, and with the ARVO (The Association for Research in Vision and Ophthalmology) statement on the use of animals in ophthalmic and vision research.

\section{Vitreous substitutes}

Healaflow ${ }^{\circledR}$ (Aptissen S.A., Plan Les Ouates, Switzerland) is a transparent hydrogel, developed and marketed for use in glaucoma filtering surgery, where its purpose is to maintain the bleb and limit postoperative fibrosis [32-34]. In this application, the gel is retained for 3-6 months [33], whereas it was retained in the vitreous space for at least a few weeks when evaluated as an experimental vitreous substitute [26]. The hydrogel consists of over $97 \%$ water, sodium hyaluronic acid $(22.5 \mathrm{mg} / \mathrm{ml})$ of non-animal origin cross-linked with BDDE (1,4-Butanediol diglycidyl ether), and phosphate and $\mathrm{NaCl}$ salts to maintain physiological $\mathrm{pH}$ (7.0) and osmolarity (305 mOsm $/ \mathrm{kg}$ ). Estimated specific gravity is circa 1.03, and refractive index $i=1.341$.

Bio-Alcamid $\AA$ (Polymekon, Brindisi, Italy) is a clear hydrogel, formerly used in plastic and reconstructive surgery as a tissue filler, mainly for lipoatrophic and posttraumatic conditions. The hydrogel consists of approximatively $4 \%$ reticulated polyalkylimide and approximately $96 \%$ non-pyrogenic water (pH 6.9), and is considered to contain no free monomers, and to be physically and chemically stable [35]. A collagen capsule the unoperated left eye of a surgically treated rabbit labeled with CD45 and Galactein-3, arrow indicates CD45+ cell on the ILM (f). GCL ganglion cell layer, INL inner nuclear layer, ONL outer nuclear layer. Scale bar is $50 \mu \mathrm{m}$

surrounding the implanted Bio-Alcamid ${ }^{\circledR}$ is formed in vivo [36]. The usage decreased following the publication of several reports that described late complications after clinical use [37-39], and the product is not currently available commercially. The stock used in this study was obtained previously.

Silicone oil, 1000 cSt (FCI S.A.S., Paris, France), is a wellestablished tamponade for vitreoretinal surgery. It is especially suitable when a long-term tamponade is indicated, such as complicated cases of retinal detachment and severe diabetic retinopathy $[40,41]$.

\section{Surgery}

Two experienced surgeons (HB and SC) performed all surgical procedures. General anesthesia was used with a combination of ketamine $(35 \mathrm{mg} / \mathrm{kg})$ and xylazine $(5 \mathrm{mg} / \mathrm{kg})$ intramuscularly. Surgery was performed on the right eyes of the

Fig. 2 Cryosections of rabbit retina labeled with hematoxylin and eosin: routine vitrectomy with BSS after 1 day (a), 1 week (b), and 1 month (c). Healaflow ${ }^{\circledR}$ treatment after 1 day (d), 1 week (e), and 1 month (f). Silicone oil treatment after 1 day (g), 1 week (h), and 1 month (i). BioAlcamid® treatment after 1 week (j) and 1 month $(\mathbf{k})$. Vitrectomy with significant retinal perioperative complications and BSS: large RD after 1 day (I), retinal break after 1 week (m), and the edge of a retinal break after 1 month (n). GCL ganglion cell layer, INL inner nuclear layer, ONL outer nuclear layer. Scale bar is $50 \mu \mathrm{m}$ 
a

1 DAY b

1 WEEK C

1 MONTH
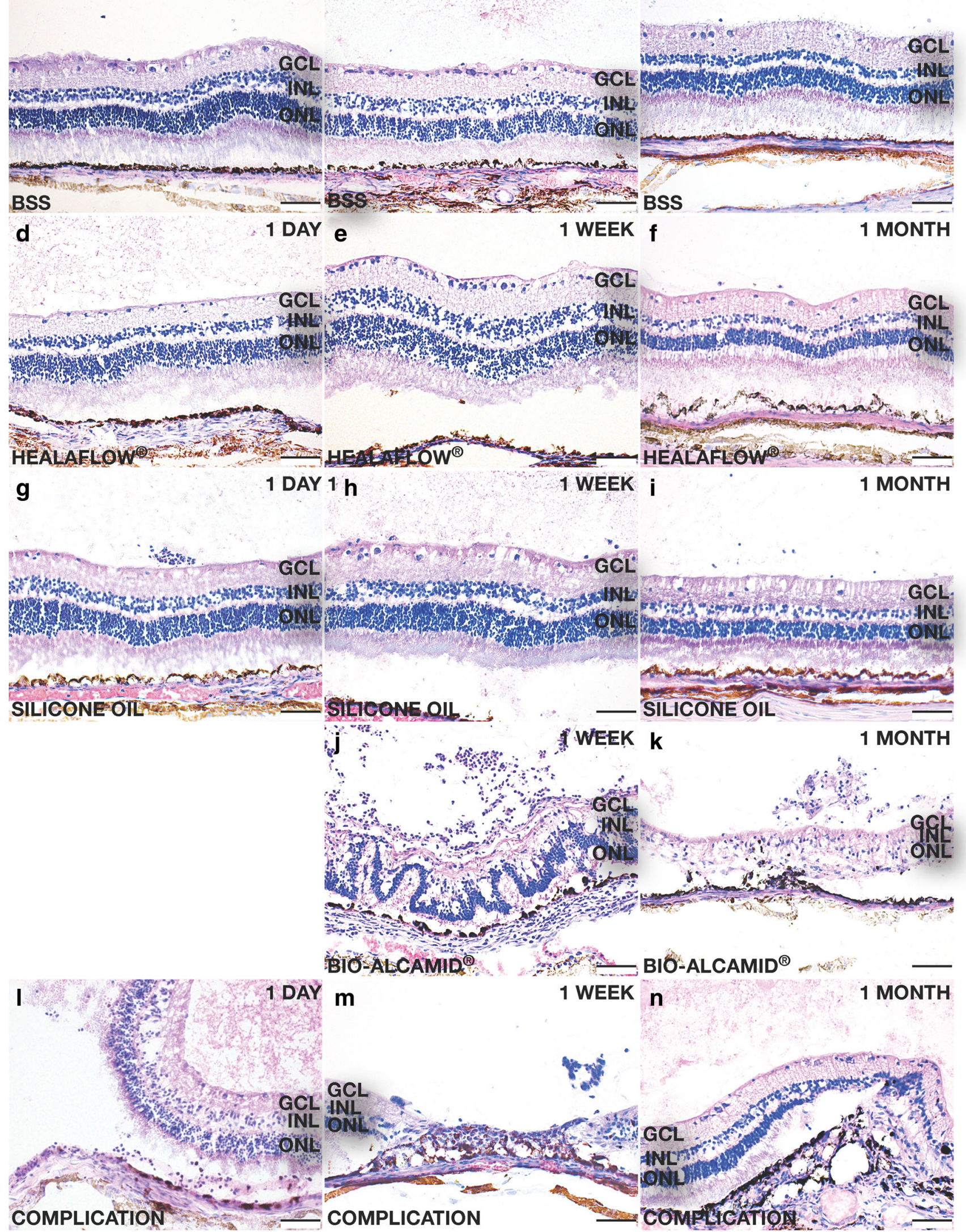
rabbits, while the left eyes served as controls. The pupils of the eyes were dilated with cyclopentolate $(1 \%)$ and phenylephrine (10\%) $30 \mathrm{~min}$ prior to surgery. Topical anesthesia with tetracaine $(0.5 \%)$ was applied just before surgery. Sclerotomies for the infusion and the illumination probe were made with two transconjunctival $25 \mathrm{G}$ trocars $1 \mathrm{~mm}$ posterior to the limbus (at 2 and 12 o'clock). For the main instrument, a sclerotomy was created with either a transconjunctival $25 \mathrm{G}$ trocars, or a conjunctival cut and subsequent $19 \mathrm{G}$ scleral incision (at 10 o'clock).

A BIOM 90-D lens (Oculus, Wetzlar, Germany) along with a standard endoilluminating probe were used for visualization. The Accurus Surgical System (Alcon, Fort Worth, TX, USA) with a vitreous cutter (Accurus 2500, Alcon, Fort Worth, TX, USA) was used, together with a continuous infusion of balanced salt solution (BSS plus, Alcon, Fort Worth, TX, USA). Core vitrectomy with posterior vitreous detachment (PVD) was performed, leaving peripheral parts of the vitreous intact due to the increased risk of traumatic cataract with the comparatively large lens of the rabbit. After a fluid-air exchange, approximately $0.5-1.0 \mathrm{ml}$ of BSS $(n=14)$, Healaflow ${ }^{\circledR}(n=12)$, or 1000 cSt silicone oil $(n=12)$ was injected into the vitreous cavity through a $25 \mathrm{G}$ needle. Bio-Alcamid $®(n=8)$ was not possible to inject through the $25 \mathrm{G}$ system due to its high viscosity. To accommodate for this, a modified cannula positioned through a $19 \mathrm{G}$ sclerotomy was used, and the sclera and conjunctiva were closed with sutures at the end of the surgery. Limited touching of the crystalline lens $(n=8)$, and minor retinal touches $(n=8)$ occurred in some of the eyes slated for treatment for treatment with Healaflow ${ }^{\circledR}$, silicone oil, and Bio-Alcamid $®($ Table 1). In addition, 4 eyes with limited lens touches were kept in the BSS group, while 14 eyes with significant perioperative complications (inadvertent displacement of the infusion into the subretinal space with subsequent retinal detachment (RD) $(n=2)$, significant retinal break $(n=13)$, and significant lens touch $(n=1))$ were filled with BSS and analyzed separately (Table 1). Chloramphenicol ointment (Chloromycetin, Pfizer Inc., NY, USA) was applied immediately after surgery. No other postoperative treatment was given.

\section{Postoperative handling and tissue processing}

Clinical evaluation with ophthalmoscopy and intraocular pressure (IOP) measurement (Tono-Pen ${ }^{\circledR}$ ) was performed postoperatively after 1 day, 1 week, and 1 month. At these time points, 4-6 rabbits in each group were euthanized. Due to the lack of a sufficient number of Bio-Alcamid®-filled eyes, no rabbits in this group were euthanized at the 1-day time point. At termination, the eyes were enucleated, examined macroscopically, photographed, dissected, and prepared for histological examination with routine microscopy and immunohistochemistry. In addition to the operated eyes, a total of 24 unoperated fellow eyes were processed for histology, with at
Fig. 3 Cryosections of rabbit retina labeled with glial fibrillary acidic protein (GFAP, activated Müller cells): routine vitrectomy with BSS after 1 day (a), 1 week (b), and 1 month (c). Healaflow ${ }^{\circledR}$ treatment after 1 day (d), 1 week (e), and 1 month (f). Silicone oil treatment after 1 day $(\mathbf{g}), 1$ week $(\mathbf{h})$, and 1 month (i). Bio-Alcamid ${ }^{\circledR}$ treatment after 1 week (j) and 1 month $(\mathbf{k})$. Vitrectomy with significant complications and BSS in eyes with: retinal break after 1 day (l), limited RD after 1 week (m), and retinal break after 1 month (n). GCL ganglion cell layer, INL inner nuclear layer, ONL outer nuclear layer. Scale bar is $50 \mu \mathrm{m}$

least one sample from each group at each time point. These samples, together with at least one sample obtained from eyes of animals not subjected to surgery for each immunohistochemical marker, were used as controls.

The eyes were dissected vertically between the ora serrata regions including the optic nerve head and visual steak, and fixed for $4 \mathrm{~h}$ with $4 \%$ paraformaldehyde $\mathrm{pH} 7.3$ in a $0.1 \mathrm{M}$ Sørensen's phosphate buffer (PB), and then repeatedly washed with $0.1 \mathrm{M}$ Sørensen's PB using the same solution containing sucrose of rising concentrations $(5-25 \%)$. The specimens were sectioned at $12 \mu$ on a cryostat, and every 10th slide was stained with hematoxylin and eosin according to standard procedures.

For immunohistochemical labeling, sections were washed in room temperature with $0.1 \mathrm{M}$ of sodium phosphatebuffered saline $\mathrm{pH} 7.2$ (PBS) with $0.1 \%$ Triton X-100 (PBS/ Triton), and incubated overnight at $+4{ }^{\circ} \mathrm{C}$ with antibodies against the following antigens: CD45 (pan-leukocyte) double-labeled with galectin-3 (mainly microglia), CD68 (macrophages), CD20 (B lymphocytes), and GFAP (activated Müller cells), diluted with PBS/Triton with $1 \%$ bovine serum albumin (Table 2). After incubation with the primary antibodies, the specimens were rinsed with PBS/Triton, and the slides were thereafter incubated with fluorescein isothiocyanate (FITC)-conjugated antibodies (Sigma-Aldrich, St. Louis, MO, USA) for $45 \mathrm{~min}$, rinsed, and mounted in anti-fading mounting media (VECTASHIELD, Vector Laboratories, Inc., Burlingame, CA, USA). For the double-labeling, the same procedure was performed with both of the primary antibodies, and in the latter step, both of the secondary antibodies (FITC-, and Texas Red-conjugated) added at the same time.

Negative controls were obtained by performing the same procedure as above but without any primary antibodies. A grading system was used for immunohistochemical analysis with the following designation for the estimated levels: $(+)$ sporadic, + low, ++ moderate, +++ high, and ++++ very high (Table 3).

\section{Results}

\section{Macroscopic findings (Table 1)}

Eyes filled with BSS, as well as those treated with silicone oil, and eyes treated with Healaflow ${ }^{\circledR}$, exhibited slight to moderate 


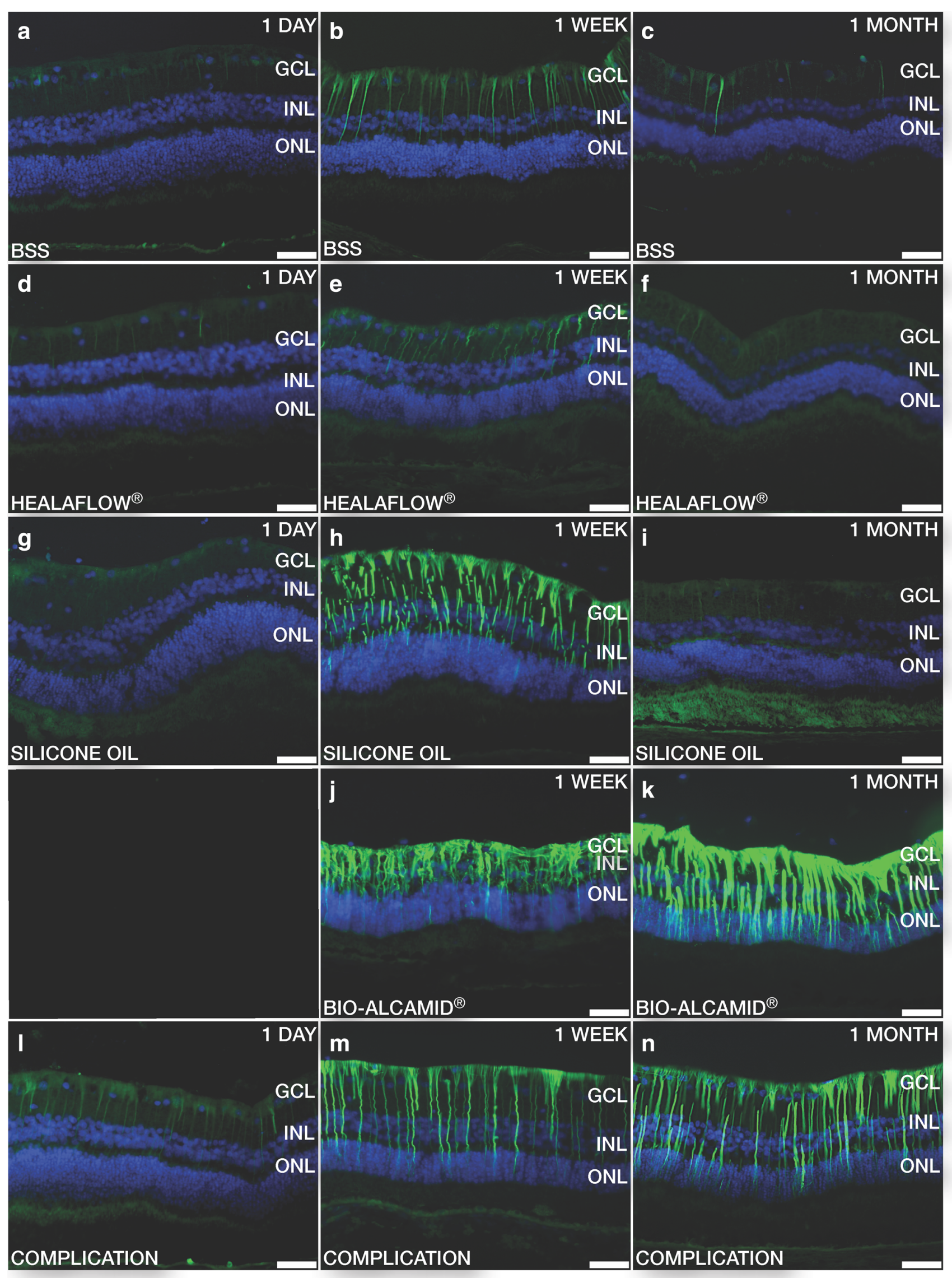


conjunctival swelling and occasional subconjunctival hemorrhage on the first day after surgery. The corneas were clear, and there were no overt signs of inflammation in the anterior chambers or the vitreous upon inspection macroscopically, and with binocular ophthalmoscopy. Mild vitreous hemorrhage was present in four cases. At later time points, there were no visible signs of superficial or intraocular inflammation, except in one eye treated with BSS which sustained severe cataract, uveitis, and possible endophthalmitis after 1 week. This animal was euthanized and excluded from further analysis. All of the eyes treated with Bio-Alcamid® exhibited signs of macroscopic inflammation such as conjunctival edema and injection. Additionally, all of these eyes showed cloudiness or suspect infiltrates in the vitreous. After a month, one of these eyes sustained massive inflammation with severe injection, conjunctival swelling, and corneal decompensation. The group of 13 eyes with significant perioperative retinal complications was macroscopically comparable to the BSS and Healaflow ${ }^{\circledR}$ groups.

Cataract formation was common especially in eyes with known perioperative touching of the lens, in some cases, hampering the view to the vitreous and retina. Two out of four eyes treated with BSS and Healaflow ${ }^{\circledR}$, respectively, and all four treated with silicone oil remained clear after a month. All eyes filled with Bio-Alcamid® displayed cataract from 1 week and onwards. In the group that sustained significant perioperative retinal complications, a higher number of eyes had intraoperative touching of the lens and subsequent severe cataract formation. At 1 month, only one of these eyes remained completely clear.

\section{Overall histology and immunohistochemistry (Table 3)}

Hematoxylin- and eosin-stained sections in unoperated in vivo controls displayed the expected normal morphology with preserved structure and lamination throughout the retina, and no pyknosis (Fig. 1a). A similar appearance was observed in eyes treated with BSS, Healaflow ${ }^{\circledR}$, and silicone oil at all time points (Table 3, Fig. 2). In many of these eyes, especially the ones treated with silicone oil, clusters of cells were seen on the inner surface of the retina (Fig. 2a-i). Bio-Alcamid®-treated eyes exhibited a severely affected morphology with regions of profound thinning, disturbed lamination, and degeneration already at 1 week after surgery, progressing at the 1-month time point (Fig. $2 \mathrm{j}-\mathrm{k}$ ). These eyes also revealed a higher amount of cells on the inner retinal surface. In the 13 eyes with perioperative retinal complications, corresponding lesions such as retinal ruptures and RDs were seen with concurrent disturbances in the retinal lamination and severe degeneration in the affected areas (Fig. 21-n).

Very low to no GFAP labeling was seen in unoperated control eyes (Fig. 1b), whereas labeling was present in almost
Fig. 4 Cryosections of rabbit retina co-labeled with CD45 (panleukocyte) (green) and Galactein-3 (mainly microglia) (red): routine vitrectomy with BSS after 1 day (a), 1 week (b), and 1 month (c). Healaflow ${ }^{\circledR}$ treatment after 1 day $(\mathbf{d}), 1$ week (e), and 1 month (f). Silicone oil treatment after 1 day (composite; representative retina left, clustering of CD45+ cells at the optic nerve head right) (g), 1 week (h), and 1 month (i). Bio-Alcamid® treatment after 1 week (j), and 1 month with arrow indicating multi-nucleated giant cell (k). Vitrectomy with significant complications and BSS in eyes with retinal break after 1 day (I), retinal break after 1 week (m), and retinal break after 1 month (composite; representative retina left, localized infiltration of CD45+ cells at a retinal break right) (n). GLC ganglion cell layer, INL inner nuclear layer, ONL outer nuclear layer. Scale bar is $50 \mu \mathrm{m}$

all eyes that had gone through surgery (Table 3, Fig. 3). BSSfilled eyes, as well as those treated with Healaflow ${ }^{\circledR}$, exhibited very low to low GFAP labeling in the inner retinal layers 1 day after surgery. After 1 week, moderately increased labeling was visible throughout the inner retina towards the outer plexiform layer (OPL). Heterogeneous minimal labeling remained in these layers after 1 month (Fig. 3a-f). Eyes treated with silicone oil displayed a similar labeling pattern at 1 day and 1 month, but with higher labeling at 1 week compared to those treated with BSS or Healaflow ${ }^{\circledR}$ (Fig. 3g-i). In eyes filled with Bio-Alcamid®, GFAP labeling revealed very high expression both at 1 week and 1 month postoperatively (Fig. 3j-k). The BSS-treated eyes with significant perioperative retinal complications showed a higher rate of labeling at all time points compared to eyes filled with BSS or Healaflow ${ }^{\circledR}$, increasing over time with sustained high labeling present from 1 week to 1 month (Fig. 31-n).

Galectin-3 labeling was not visible in unoperated control eyes (Fig. 1c). All operated eyes exhibited, in contrast to this, general diffuse labeling, especially in the inner retinal layers with no apparent difference between groups (Table 3, Fig. 4).

CD45 labeling was present in all eyes, with and without surgery (Table 3, Fig. 4), whereas only weak CD45 labeling of dendritic cells was observed in the inner retina (ganglion cell layer [GCL] and inner plexiform layer [IPL]) of unoperated eyes (Fig. 1c). In contrast to eyes from animals not subjected to surgery, all unoperated left eyes from the different study groups exhibited CD45-labeled cells in the inner retina and occasional cells on the inner limiting membrane (ILM) (Fig. 1f). All operated eyes displayed increased labeling in the inner retina, frequently with additional CD45 labeling of round cells on the ILM, and in the vitreous space (Fig. 4). Eyes treated with BSS, as well as those treated with Healaflow ${ }^{\circledR}$ exhibited low to moderate CD45 labeling at all time points (Fig. 4a-f). Silicone oil-treated eyes displayed moderate to high CD45 positivity in the inner retina on day 1, especially on the ILM, with the most pronounced labeling close to the optic nerve head (Fig. 4g, right). The CD45 labeling was high at 1 week, and again moderate to low at 1 month (Fig. $4 \mathrm{~g}-\mathrm{i}$ ). All eyes treated with Bio-Alcamid® treatment showed very highCD45 labeling intensity at 1 week and 1 month. In these eyes, 


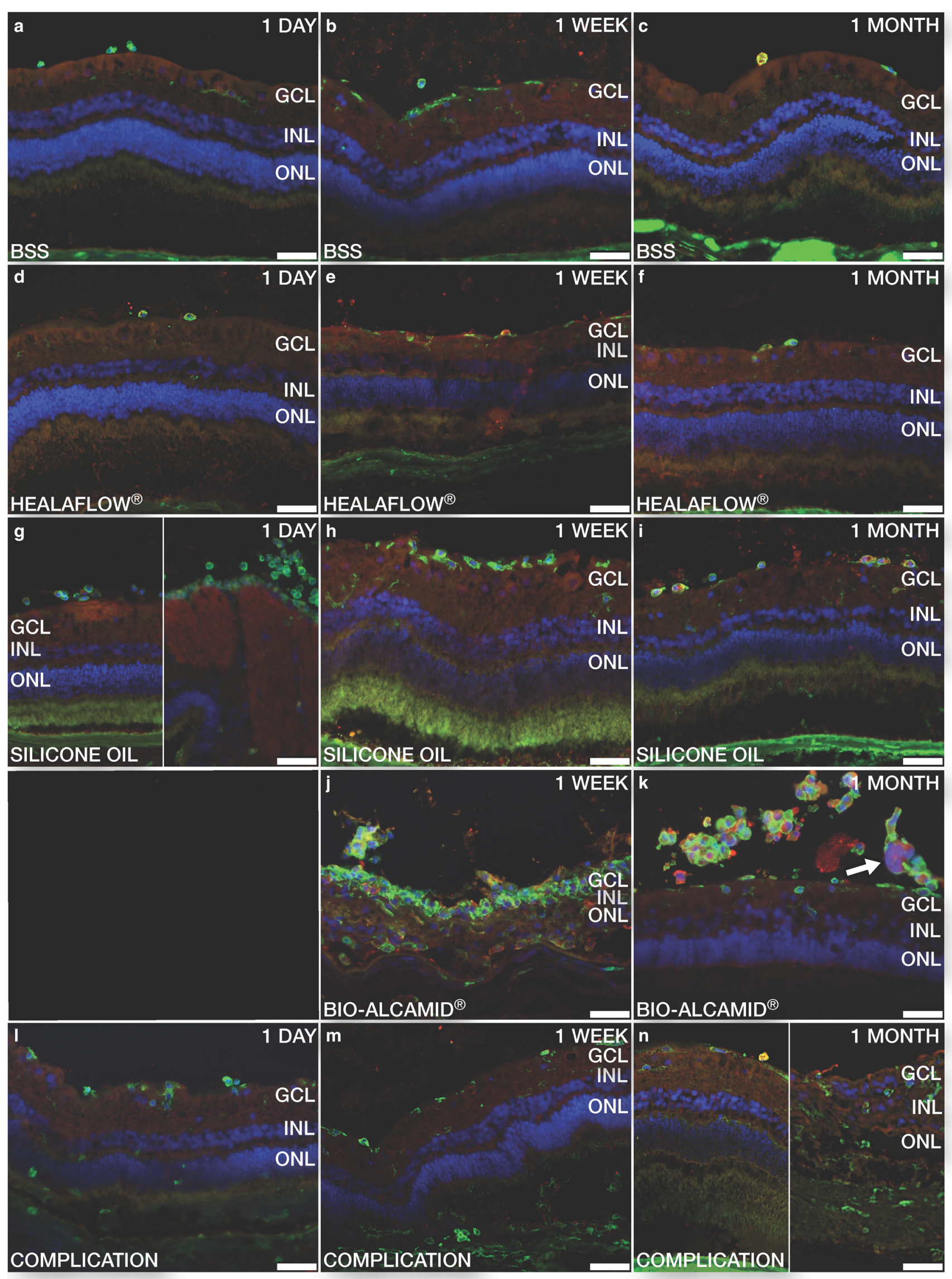


labeling revealed both dendritic and round cells often spread throughout the entire retina, and enlarged multi-nucleated giant cells in the vitreous (Fig. 4j-k). In eyes with significant perioperative complications, the CD45 labeling was heterogeneous with moderate levels of labeled cells in the inner retina and on the ILM (Fig. 41-n). There was a considerable regional variation in the labeling with aggregation of labeled cells in the vicinity of retinal lesions, where the labeling occurred in these layers as well as in deeper parts of the retina (Fig. 4n, right). Additionally, there were some eyes with occasional clusters of cells on the ILM and a tendency to form giant cells.

CD68 positive cells were seen sparingly in most operated eyes but not in unoperated controls (Table 3, Figs. 1d and 5). Labeled cells were found mainly in the inner retina, and in the vitreous. No distinct differences were seen between the eyes treated with BSS, Healaflow ${ }^{\circledR}$, or silicone oil. All the eyes treated with Bio-Alcamid® exhibited extensive CD68 labeling, mostly in the vitreous and in the areas of the retina with most pronounced thinning and structural degeneration (Fig. $5 \mathrm{j}-\mathrm{k})$. In most eyes with significant perioperative retinal complications such as retinal breaks and RDs, increased labeling was present in parts of the retinas, mainly in the vitreous space, and on the ILM (Fig. 51-n). No definite differences were seen between the different time points.

CD20 labeling was not present in unoperated eyes (Fig. 1e). A few labeled cells were present in a minority of the eyes treated with BSS, Healaflow ${ }^{\circledR}$, and silicone oil. The majority of these cells was found in the vitreous space, in some cases in the GCL, and they were almost exclusively found at the first postoperative day. In the eyes treated with Bio-Alcamid $\AA$, extensive labeling with $\mathrm{CD} 20$ was present after a week. Few distinctly labeled cells remained after a month, although intense autofluorescence was present in multi-nucleated giant cells, and in some of the most degenerated parts of the retinas (Fig. $6 \mathrm{j}-\mathrm{k}$ ). CD20+ cells were detected on the first postoperative day in two of the eyes with significant perioperative retinal complications, with moderate labeling in one eye with RD. After 1 week, low labeling remained in one eye with both a rupture and $\mathrm{RD}$, but none in other cases. No labeling was observed in this group after 1 month (Fig. 61-n).

\section{Discussion}

In this study, we have used a rabbit model to explore immunological reactions elicited by vitrectomy with the concurrent use of different vitreous substitutes. Anti-inflammatory treatment was avoided, with intention not to interfere with the natural course of inflammation after vitrectomy, thus reflecting an aspect of the normal healing processes seldom studied in the past. We found vitrectomy-elicited immune activation detectable for at least a month, even in uncomplicated
Fig. 5 Cryosections of rabbit retina labeled with CD68 (macrophages): routine vitrectomy with BSS after 1 day (a), 1 week (b), and 1 month (c). Healaflow ${ }^{\circledR}$ treatment after 1 day $(\mathbf{d}), 1$ week (e), and 1 month (f). Silicone oil treatment after 1 day (g), 1 week (h), and 1 month (i). BioAlcamid ${ }^{\circledR}$ treatment after 1 week (j) and 1 month $(\mathbf{k})$. Vitrectomy with significant complications and BSS in eyes with large RD after 1 day (l), limited RD after 1 week (m), and subtotal RD after 1 month (n). GCL ganglion cell layer, INL inner nuclear layer, ONL outer nuclear layer. Scale bar is $50 \mu \mathrm{m}$

cases treated with BSS. Similar responses are also present in eyes treated with vitreous substitutes previously considered to have clinically acceptable biocompatibility profiles.

We have earlier investigated several vitreous substitutes in vivo, as well as in vitro [24-26, 42]. Here, we further characterize inflammatory reactions by utilizing five immunohistochemical markers for different aspects of the immune system. A difference in immune activation is made evident with these markers, as Healaflow ${ }^{\circledR}$ and BSS induced only minimal inflammation, whereas silicone oil and Bio-Alcamid ${ }^{\circledR}$ elicited more potent immune responses, reflecting the differences in their biocompatibility profiles. In addition, the investigated inflammatory markers correlate well with the degree of imposed retinal damage, as seen in the group with retinal breaks and detachment. The retinal response to direct surgical trauma is localized to the area of injury, but otherwise comparable to those elicited by pro-inflammatory endotamponades. Interestingly, an immune response in the form of CD45+ cells was found on the retinal surface of all unoperated fellow eyes, but not in eyes from animals that had not been subjected to surgery, indicating that immune activation secondary to the surgical trauma may reach beyond the vitreous of the operated eye.

The retina-intrinsic immune response to the surgical trauma was characterized by upregulation of GFAP, indicating an early gliotic reaction by activation of Müller cells. GFAP upregulation has previously been described after vitrectomy combined with lensectomy, and also after vitrectomy alone [27, 43]. We here found a modest upregulation at 7 days after surgery, even in BSS- and Healaflow ${ }^{\circledR}$-filled eyes, with a substantially diminished response at 1 month, indicating transient Müller cell activation. In contrast, stronger but likewise transient GFAP upregulation was found in silicone oil-treated eyes, whereas Bio-Alcamid®-filled eyes displayed massive labeling, which did not diminish over time. In addition to the GFAP upregulation, we found galectin-3 upregulation in all operated eyes. Galectin-3 is a protein with several essential functions for physiological, as well as pathological processes including macrophage activation, fibrosis, apoptosis, cell-cell adhesion, and cell-matrix interaction [28]. To our knowledge, galectin-3 upregulation after vitrectomy has not been previously described, and this phenomenon may indicate a neuroinflammatory response within the retina that is separate from gliosis [44]. 


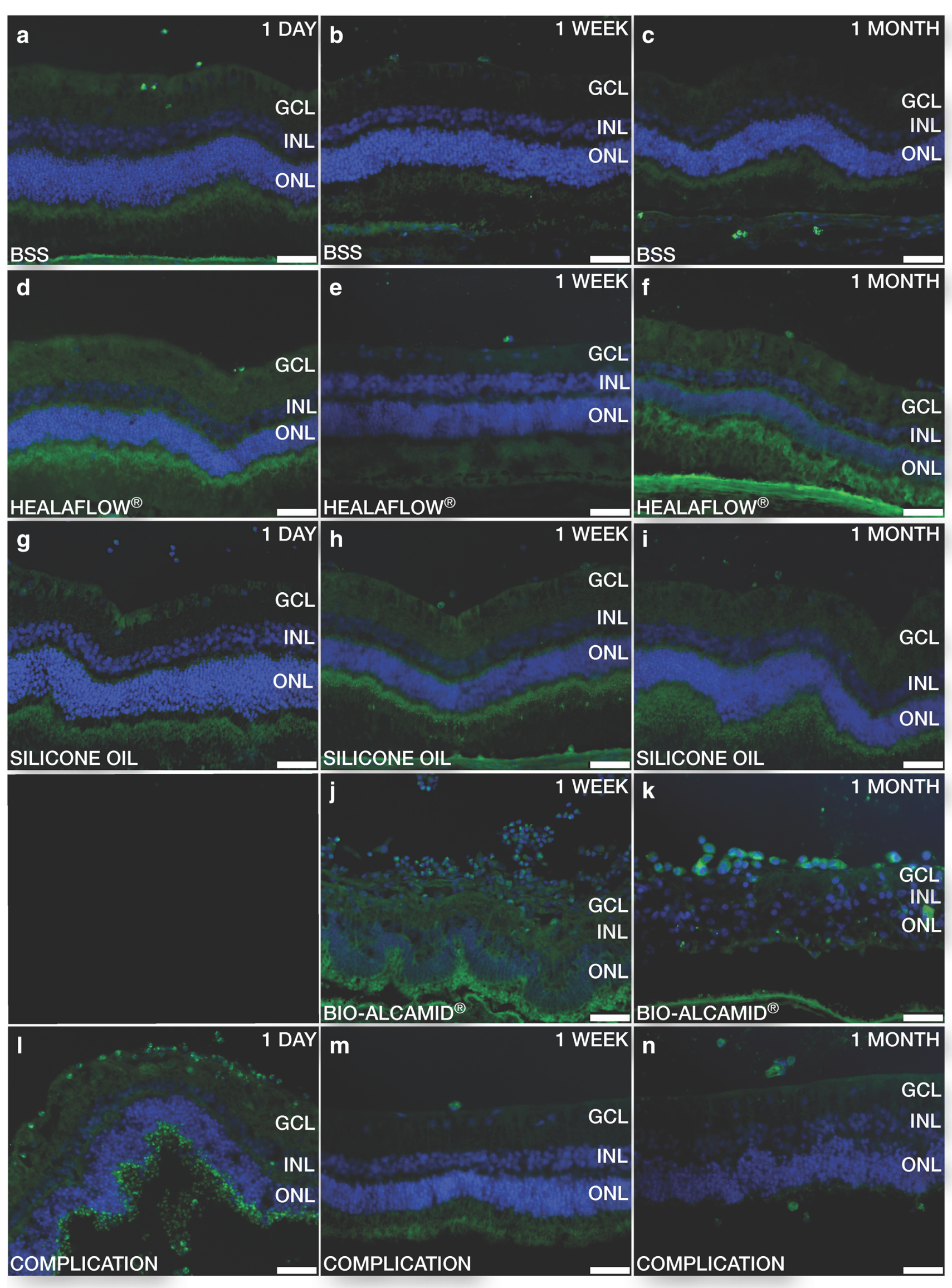




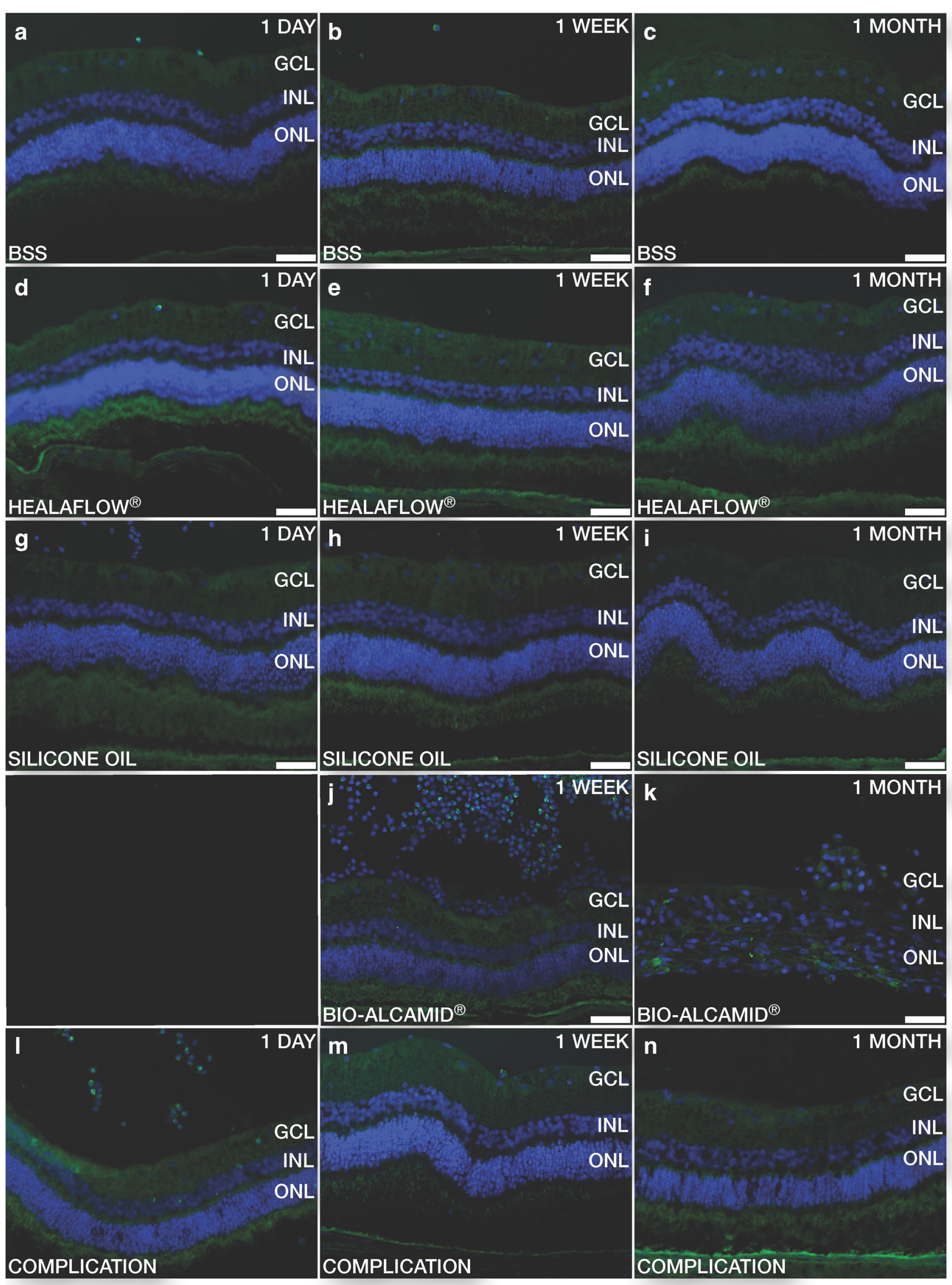


Fig. 6 Cryosections of rabbit retina labeled with CD20 (B-lymphocytes): routine vitrectomy with BSS after 1 day (a), 1 week (b), and 1 month (c). Healaflow ${ }^{\circledR}$ treatment after 1 day $(\mathbf{d}), 1$ week (e), and 1 month (f). Silicone oil treatment after 1 day (g), 1 week (h), and 1 month (i). BioAlcamid® treatment after 1 week (j) and 1 month $(\mathbf{k})$. Vitrectomy with significant complications and BSS in eyes with large RD after 1 day (l), limited RD after 1 week (m), and retinal break after 1 month (n). GCL ganglion cell layer, INL inner nuclear layer, ONL outer nuclear layer. Scale bar is $50 \mu \mathrm{m}$

Immune responses following vitrectomy were not, however, limited to retina-intrinsic reactions. In accordance, previous studies have shown increased gliosis (GFAP-labeling) as well as increased presence of cellular antigens such as CD45 and CD68 in samples from patients with proliferative vitreoretinopathy (PVR) [45]. To explore the cellular involvement, we investigated three $\mathrm{CD}$ antigens with various roles in inflammation pathology. The cellular immune response after surgery was most evident in the CD45 labeling, followed by CD68 and CD20. In accordance with the GFAP result, and with previous work, cellular inflammation was strongest in BioAlcamid®-filled eyes, followed by those treated with silicone oil [23, 24, 37, 46]. The similar labeling pattern between CD45, a pan-leukocyte antigen, and CD68, a marker for cells of the macrophage lineage, as seen in these two groups indicates that a significant part of the cellular inflammatory response might consist of phagocytes. The specific origin of these inflammatory cells is outside the scope of this study, but might include activation of microglia, migration of monocytes from the choroidal circulation, as well as hyalocytes from the remnants of the peripheral vitreous. CD20, generally expressed in most Blymphocytes, was almost exclusively found in Bio-Alcamid®filled eyes, again highlighting its potential for immune activation. Although the increased surgical trauma caused by the $19 \mathrm{G}$ sclerotomies might be a contributing factor in the more pronounced inflammatory responses of Bio-Alcamid®-treated eyes, adverse effects of the gel are likely the main cause, considering the retinal effects in earlier studies [24, 25].

The potent immune response to Bio-Alcamid® might at least in part be due to a foreign body response, as evident by the presence of multi-nucleated giant cells. Bio-Alcamid ${ }^{\circledR}$ is known to cause a fibrotic capsule and chronic inflammation when used as a soft tissue filler in esthetic and reconstructive surgery, and is for this reason no longer in clinical use [38, 39]. In silicone oil-treated eyes, CD45+ cells were often clustered at the optic nerve head. These findings are congruent with earlier publications where silicone oil has been shown to cause foreign body reactions and giant cell granulomas in the optic nerve among other locations [9, 46]. The similar findings, albeit of different magnitudes, in eyes treated with silicone oil and Bio-Alcamid® might suggest that a foreign body reaction can play a role in the pathological response to some substances with radically different composition compared to the natural vitreous. In contrast and also in accordance with the GFAP results, only minimal CD labeling was found in BSS and Healaflow ${ }^{\circledR}$ counterparts, once more confirming the excellent biocompatibility of these vitreous substitutes. Compared with silicone oil and Bio-Alcamid ${ }^{\circledR}$, Healaflow ${ }^{\circledR}$ has a structure and composition similar to the natural vitreous, which may account for its excellent biocompatibility. An increased understanding of normal and pathological responses might aid in the development of more biocompatible vitreous substitutes. For the purpose of biocompatibility screening in the development of novel vitreous substitutes, GFAP combined with CD45 or CD68 seems to be a suitable combination.

Acknowledgments This work was supported by The Swedish Research Council, and The King Gustaf V and Queen Victoria Freemason Foundation. Thanks to participating investigator Hodan Abdshill for data collecting and excellent technical support.

Statements The authors have full control of all primary data, available for review by Graefe's Archive for Clinical and Experimental Ophthalmology upon request.

Funding This study was funded by Vetenskapsrådet (grant no. 90247201) and Konung Gustaf V:s och Drottning Victorias Frimurarestiftelse.

\section{Compliance with ethical standards}

All proceedings and animal treatment were in accordance with the guidelines and requirements of the government committee on animal experimentation at Lund University, and with the ARVO (The Association for Research in Vision and Ophthalmology) statement on the use of animals in ophthalmic and vision research. All applicable international, national, and/or institutional guidelines for the care and use of animals were followed. This article does not contain any studies with human participants performed by any of the authors. The "Principles of laboratory animal care" (NIH publication no. 85-23, revised 1985), the OPRR Public Health Service Policy on the Humane Care and Use of Laboratory Animals (revised 1986), and the U.S. Animal Welfare Act, as amended, were followed, as well as the current version of the Swedish Law on the Protection of Animals where applicable.

Conflict of interest The authors declare that they have no conflict of interest.

OpenAccessThis article is distributed under the terms of the Creative Commons Attribution 4.0 International License (http://creativecommons.org/ licenses/by/4.0/), which permits unrestricted use, distribution, and reproduction in any medium, provided you give appropriate credit to the original author(s) and the source, provide a link to the Creative Commons license, and indicate if changes were made.

Publisher's Note Springer Nature remains neutral with regard to jurisdictional claims in published maps and institutional affiliations.

\section{References}

1. Colthurst MJ, Williams RL, Hiscott PS, Grierson I (2000) Biomaterials used in the posterior segment of the eye. Biomaterials 21(7):649-665 
2. Jakobsson G, Sundelin K, Zetterberg H, Zetterberg M (2015) Increased levels of inflammatory immune mediators in vitreous from pseudophakic eyes. Invest Ophthalmol Vis Sci 56(5):3407-3414

3. Yasuda K, Motohashi R, Kotake O, Nakagawa H, Noma H, Shimura M (2016) Comparative effects of topical diclofenac and betamethasone on inflammation after vitrectomy and cataract surgery in various vitreoretinal diseases. J Ocul Pharmacol Ther 32(10):677-684

4. Ben Yahia S, Kahloun R, Abroug N, Kaibi I, Laadhari G, Jelliti B, Khairallah M (2016) Comparative effect of topical diclofenac and topical dexamethasone on anterior chamber flare and postoperative pain following rhegmatogenous retinal detachment surgery. Int Ophthalmol 36(5):623-628

5. Hoerster R, Hermann MM, Rosentreter A, Muether PS, Kirchhof B, Fauser S (2013) Profibrotic cytokines in aqueous humour correlate with aqueous flare in patients with rhegmatogenous retinal detachment. Br J Ophthalmol 97(4):450-453

6. Killey FP, Edelhauser HF, Aaberg TM (1978) Intraocular sulfur hexafluoride and octofluorocyclobutane. Effects on intraocular pressure and vitreous volume. Arch Ophthalmol 96(3):511-515

7. Riedel KG, Gabel VP, Neubauer L, Kampik A, Lund OE (1990) Intravitreal silicone oil injection: complications and treatment of 415 consecutive patients. Graefes Arch Clin Exp Ophthalmol 228(1):19-23

8. Liu Z, Fu G, Liu A (2017) The relationship between inflammatory mediator expression in the aqueous humor and secondary glaucoma incidence after silicone oil tamponade. Exp Ther Med 14(6):58335836

9. Wickham LJ, Asaria RH, Alexander R, Luthert P, Charteris DG (2007) Immunopathology of intraocular silicone oil: retina and epiretinal membranes. Br J Ophthalmol 91(2):258-262

10. Asaria RH, Kon CH, Bunce C, Sethi CS, Limb GA, Khaw PT, Aylward GW, Charteris DG (2004) Silicone oil concentrates fibrogenic growth factors in the retro-oil fluid. Br J Ophthalmol 88(11):1439-1442

11. Papp A, Kiss EB, Tímár O, Szabó E, Berecki A, Tóth J, Páli J (2007) Long-term exposure of the rabbit eye to silicone oil causes optic nerve atrophy. 74(1-3):130-133

12. Nakamura K, Refojo MF, Crabtree DV, Pastor J, Leong FL (1991) Ocular toxicity of low-molecular-weight components of silicone and fluorosilicone oils. Invest Ophthalmol Vis Sci 32(12):3007-3020

13. Ghoraba HH, Zaky AG, Heikal MA, Elgemai EEM, Abd Al Fatah HM (2017) Silicone oil-related visual loss. Ophthalmologica 238(1-2):59-67

14. Swindle KE, Ravi N (2007) Recent advances in polymeric vitreous substitutes. Exp Rev Ophthalmol 2(2):255-265

15. Chirila TV, Tahija S, Hong Y, Vijayasekaran S, Constable IJ (1994) Synthetic polymers as materials for artificial vitreous body: review and recent advances. J Biomater Appl 9(2):121-137

16. Versura P, Cellini M, Torreggiani A, Bernabini B, Rossi A, Moretti M, Caramazza R (2001) The biocompatibility of silicone, fluorosilicone and perfluorocarbon liquids as vitreous tamponades. An ultrastructural and immunohistochemical study. Ophthalmologica 215(4):276-283

17. Anderson JM, Rodriguez A, Chang DT (2008) Foreign body reaction to biomaterials. Semin Immunol 20(2):86-100

18. Thackaberry EA, Farman C, Zhong F, Lorget F, Staflin K, Cercillieux A, Miller PE, Schuetz C, Chang D, Famili A, Daugherty AL, Rajagopal K, Bantseev V (2017) Evaluation of the toxicity of intravitreally injected PLGA microspheres and rods in monkeys and rabbits: effects of depot size on inflammatory response. Invest Ophthalmol Vis Sci 58(10):4274-4285

19. Elsing SH, Fekrat S, Green WR, Chang S, Wajer SD, Haller JA (2001) Clinicopathologic findings in eyes with retained perfluoron-octane liquid. 108(1):45-8

20. Sigler EJ, Randolph JC, Charles S (2014) Foreign body response within postoperative perfluoro-N-octane for retinal detachment repair: clinical features, grading system, and histopathology. Retina 34(2):237-246

21. Schatz B, El-Shabrawi Y, Haas A, Langmann G (2004) Adverse side effects with perfluorohexyloctane as a long-term tamponade agent in complicated vitreoretinal surgery. Retina 24(4):567-573

22. Parmley VC, Barishak YR, Howes EL Jr, Crawford JB (1986) Foreign-body giant cell reaction to liquid silicone. Am J Ophthalmol 101(6):680-683

23. Srinivasan S, Singh AK, Desai SP, Talbot JF, Parsons MA (2003) Foreign body episcleral granulomas complicating intravitreal silicone oil tamponade: a clinicopathological study. Ophthalmology 110(9): $1837-1840$

24. Crafoord S, Andreasson S, Ghosh F (2011) Experimental vitreous tamponade using polyalkyl-imide hydrogel. Graefes Arch Clin Exp Ophthalmol 249:1167-1174

25. Barth H, Crafoord S, O'Shea TM, Pritchard CD, Langer R, Ghosh F (2014) A new model for in vitro testing of vitreous substitute candidates. Graefes Arch Clin Exp Ophthalmol 252(10):1581-1592

26. Barth H, Crafoord S, Andréasson S, Ghosh F (2016) A cross-linked hyaluronic acid hydrogel (Healaflow $\left.{ }^{\circledR}\right)$ as a novel vitreous substitute. Graefes Arch Clin Exp Ophthalmol 254(4):697-703

27. Durlu YK, Ishiguro S, Yoshida A, Mito T, Tsuchiya M, Tamai M (1990) Response of Müller cells following experimental lensectomy-vitrectomy. Graefes Arch Clin Exp Ophthalmol 228(1):44-48

28. Uehara F, Ohba N, Ozawa M (2001) Isolation and characterization of galectins in the mammalian retina. Invest Ophthalmol Vis Sci 42(10):2164-2172

29. Chen L, Yang P, Kijlstra A (2002) Distribution, markers, and functions of retinal microglia. Ocul Immunol Inflamm 10(1):27-39

30. Matsuo T, Ichimura K (2012) Immunocytochemical diagnosis as inflammation by vitrectomy cell blocks in patients with vitreous opacity. Ophthalmology 119(4):827-837

31. Lim W-K, Chee S-P, Sng I, Nussenblatt RB, Chan C-C (2004) Immunopathology of progressive subretinal fibrosis: a variant of sympathetic ophthalmia. Am J Ophthalmol 138(3):475-477

32. Schariot GB (2010) Canaloplasty re-establish the natural outflow in patients with chronic open-angle Glaucoma. J Current Glau Prac 4(2):97-102

33. Roy S, Thi HD, Feusier M, Mermoud A (2012) Crosslinked sodium hyaluronate implant in deep sclerectomy for the surgical treatment of glaucoma. Eur J Ophthalmol 22(1):70-76

34. Bettin P, Di Matteo F, Rabiolo A, Fiori M, Ciampi C, Bandello F (2016) Deep sclerectomy with mitomycin C and injectable crosslinked hyaluronic acid implant: long-term results. J Glaucoma 25(6):e625-e629

35. Ramires P, Miccoli M, Panzarini E, Dini L, Protopapa C (2005) In vitro and in vivo biocompatibility evaluation of a polyalkylimide hydrogel for soft tissue augmentation. J Biomed Mater Res B Appl Biomater 72(2):230-238

36. Lahiri A, Waters R (2007) Experience with bio-Alcamid $®$, a new soft tissue endoprosthesis. J Plast Reconstr Aesthet Surg 60(6):663-667

37. Christensen L, Breiting V, Janssen M, Vuust J, Hogdall E (2005) Adverse reactions to injectable soft tissue permanent fillers. Aesthet Plast Surg 29(1):34-48

38. Karim RB, Hage JJ, van Rozelaar L, Lange CAH, Raaijmakers J (2006) Complications of polyalkylimide 4\% injections (BioAlcamid): a report of 18 cases. J Plast Reconstr Aesthet Surg 59(12):1409-1414

39. Nelson L, Stewart KJ (2011) Early and late complications of polyalkylimide gel (Bio-Alcamid)®. J Plast Reconstr Aesthet Surg 64(3):401-404

40. Kanski JJ, Daniel R (1973) Intravitreal silicone injection in retinal detachment. Br J Ophthalmol 57(8):542-545 
41. Stappler T, Morphis G, Irigoyen C, Heimann H (2011) Is there a role for long-term silicone oil tamponade for more than twelve months in vitreoretinal surgery? Ophthalmologica 226(Suppl I):36-41

42. Pritchard CD, Crafoord S, Andréasson S, Arnér KM, O'Shea TM, Langer R, Ghosh FK (2010) Evaluation of viscoelastic poly(ethylene glycol) sols as vitreous substitutes in an experimental vitrectomy model in rabbits. Acta Biomater 7:936-943

43. Guizzo R, Paques MW, Anhezini L, Simon CR, Scott IU, Jorge R, Santos WF (2008) Neuroprotective effects of oral lamotrigine administration on rabbit retinas after pars plana vitrectomy and silicone oil injection. Retina 28(4):638-644
44. Ghosh F, Abdshill H, Arnér K, Voss U, Taylor L (2018) Retinal neuroinflammatory induced neuronal degeneration - role of toll-like receptor-4 and relationship with gliosis. Exp Eye Res 169:99-110

45. Proença R, Carvalho M, Proença D, Verissimo J, Regadas I, Travassos A (1994) HLA antigens and lymphocytes in proliferative vitreoretinopathy. Graefes Arch Clin Exp Ophthalmol 232(1):25-32

46. Budde M, Cursiefen C, Holbach LM, Naumann GO (2001) Silicone oil-associated optic nerve degeneration. Am J Ophthalmol 131(3):392-394 